\title{
Active Learning as a Strategy in Embracing Diversity in Inclusion Classrooms
}

\author{
Matjhabedi E. Mazibuko \\ Vaal University of Technology, Private Bag x021, Vanderbijlpark, 1911 South Africa \\ Email: chabi.mazibuko@gmail.com
}

\section{Doi:10.5901/mjss.2014.v5n14p180}

\section{Abstract}

Active learning shifts the focus of teaching from what the teacher should bring to learners towards what do you want learners to be able to do with lesson material. Similarly, learners must enter class prepared to use assigned readings and reviewed material from past classes, etc. Not only are learners expected to be up-to-date on lesson material but to have assimilated the material so they can use and build on it. When learners recognise that the teacher's lesson involves active learning, they will also recognise that they must be active if they are to succeed in the lesson (Doyle, 2011). the teacher consider various modes of instruction, they must keep in mind that learning depends primarily on what the learners do, both in and out of class, rather than what the teacher does. The teacher's task is to select activities through which learners can master lesson objectives. Lessons, discussions, written exercises, reading exercises, tests, group work, individualized instruction, field trips, observations, experiments, and many other kinds of experiences may be necessary for learners to learn the things the teacher want them to learn.

Keywords: Active Learning; Diversity; Inclusion; Lesson material; Lesson programme.

\section{Introduction}

As multiple studies have indicated, increases in learner achievement are only one of the positive results of active learning. Braxton, Milem, and Sullivan (2000) focused their research on a review of Vincent Tinto's work on retention. Using the Bonwell and Eison definition, Braxton, Milem and Sullivan (2000: 571) examined the impact of active learning classroom approaches, specifically "class discussions, knowledge-level examination questions, group work, and higherorder thinking activities," on learner persistence and their feelings of social integration. Their results suggest that active learning may influence learners' social integration, commitment to the institution, and their decision whether to remain in school. Given such value in active learning approaches, faculty should know how to introduce them effectively.

Active learning can be applied to most commonly used lesson activities, depending on whether they involve the learner or they position the learner as a receptacle passively receiving content. For example, learners may have passively read throughout their lives, so a simple direction to annotate and interact with text may not lead learners to actively read. The teacher must show them his or her own examples of active reading, using a page from their own assigned reading. Then have the learners submit a page or two of their own active reading, at first and comment on it, showing them one more correct step in their thinking about the text or how using the text to reflect on the larger subject of the lesson can broaden and sharpen their thinking and learning (Wilson \& Korn, 2007).

Further, the teacher must make examples sufficient and competent, but not so superior to your learners' efforts that they demoralise the very listeners you are trying to stimulate. Cross-outs in the margins or in something like a journal exercise, questions that reveal your own uncertainty on an issue or about a concept can help learners see that knowledge is often constructed rather than just indicated quickly in a process available only to the chosen.

Similarly, the teacher may periodically stop discussions during the lesson and offer suggestions for how learners may have modified their comments to engage and build on what another learner has said (Berry, 2008).

\section{Essentials to Consider for Active Learning Approaches}

Before introducing active learning approaches, it is a good idea for teachers to clarify their expectations and to emphasise that the active learning techniques used in class will be used in the tests, examinations and class exercises (Cameron, 1999). The optimum place to do this is in the lesson programme, but the value of active learning approaches must be constantly reinforced. Sadly, some learners resist learner-centred teaching approaches. Doyle (2008) explores eight reasons why they might do so and offers ways to counter these negative responses, including the suggestion that Felder 
(2011) recommends. Explain to learners that their active participation will not only increase their learning, but it will also reinforce useful job skills and lead to higher grades. Yorges (2008) makes the point that clarifying learning objectives and lesson expectations and requirements up front can positively affect learner motivation.

Lang (2007) also endorses that both teachers and learners understand the reasons for main lesson decisions. Lang (2007:2) concludes that "the most effective teaching is transparent teaching". Elaborating on this idea, Zahorski (1990) indicates that if learners are to feel comfortable actively participating, then the classroom climate must also be taken into account. Ambrose, Bridges, DiPietro and Norman (2010) recommend several approaches for teachers to make uncertainty comfortable for learners, encouraging multiple answers, questioning their own assumptions, being careful not to inadvertently suggest low-learner ability, even with positive intents, refraining from asking individuals to speak for a minority, demonstrating inclusiveness by their words, actions, and attitudes, using many different examples and correlations, building a positive lesson climate early in the lesson, establishing ways for learners to offer feedback on classroom climate issues, preparing ahead of time to skilfully resolve sensitive issues, attending to any other issues as soon as they sense them and turning them into learning opportunities and always listening to learners to determine their intended meanings (Ambrose, Bridges, DiPietro \& Norman, 2010: 180-186). Next discussion will be on active learning techniques.

\section{Active Learning Techniques}

Active learning is a process wherein learners are actively engaged in building understanding of facts, ideas, and skills through the completion of teacher directed tasks and activities. It is any type of activity that gets learners involved in the learning process. Active Learning is, in short, anything that learners do in a classroom other than merely passively listening to a teacher's lesson (Bligh, 2000). This includes everything from listening practices which help the learners to absorb what they hear, to short writing exercises in which learners react to lesson material, to complex group exercises in which learners apply lesson material to real life situations or to new problems. The term cooperative learning covers the subset of active learning activities which learners do as groups of three or more, rather than alone or in pairs; generally, cooperative learning techniques employ more formally structured groups of learners assigned complex tasks, such as multiple-step exercises, research projects, or presentations (Stuart \& Rutherford, 1978).

Active learning activity is a planned series of actions or events to invite the participant to process, apply, interact and share experiences as part of the teaching and learning process. Active learning activities include a wide range of activities that share the common element of involving learners in doing things and thinking about the things they are doing. Active learning techniques can be created and used to engage learners in thinking critically or creatively, speaking with a partner, in a small group, or with the entire class, expressing ideas through writing, exploring personal attitudes and values, giving and receiving feedback and reflecting upon the learning process $\|$. When a teacher employs active learning techniques, he or she will typically spend greater proportion of time helping learners develop their understanding and skills, promoting deep learning and a lesser proportion of time transmitting information, that is, supporting surface learning. In addition, the teacher will provide opportunities for learners to apply and demonstrate what they are learning and to receive immediate feedback from peers or the teacher. (Bonwell \& Eison 1991)

Berry (2008) further postulates that four key elements characterise all active learning approaches, namely, critical thinking, individual responsibility for learning, involvement in open-ended activities and organization of learning activities by the teacher. To amplify each of these components, critical thinking can be promoted through higher-order thinking tasks predicated on Bloom's (1956) well-known taxonomy: analysis, synthesis, and evaluation. Brookfield (1987) also emphasizes that critical thinking occurs when learners find their assumptions challenged and see alternative ways of approaching problems. These two elements can be fostered through the careful use of structured group work. As indicated by Millis (2002), all four of these key characteristics occur when teachers use cooperative learning. Unlike less structured forms of collaborative learning, cooperative learning requires learners to be individually responsible for their own learning.

There are no group marks or scores without individual accountability. Any group projects involve peer assessments, self-assessments, and often whole-group assessments to determine individual contributions. Further, group work involves learners in open-ended activities that focus on problem solving. To close, because cooperative learning is highly structured, the learning activities must be carefully designed and monitored by the teacher. As Smith, Sheppard, Johnson, and Johnson (2005: 2) indicate, "engaging learners in learning is principally the responsibility of the teacher, who becomes less an imparter of knowledge and more a designer and facilitator of learning experiences and opportunities". Adopting these approaches has great rewards in terms of learner learning. 


\subsection{Peer teaching}

Peer teaching's purpose is to move the site of teaching and learning from the teacher to the learners. To have learners connect or apply concepts by explaining to another learner or trying to convince another learner. Peer instruction can be used in review lessons to move learners to a higher learning level, beyond their concern over what to memorize. Learners who are required to teach something learn concepts better than if they are taught the material in conventional ways. In other words, teaching is a more effective learning strategy than being taught and it makes sense to use this norm in the classroom to increase learning. Pairing learners at learning tasks is more effective than having learners work alone (Haak, HilleRisLambers, Pitre, \& Freeman, 2011).

Peer teaching can easily be incorporated in most classes. For example, you could make an exercise in which learners must prepare their own questions on the main points of a lesson. Have learners work in pairs or small groups, alternately asking and answering questions they have prepared. During the lesson, the teacher can move from group to group, giving feedback and asking and answering questions. Learners are more willing to share their views in small groups and often develop deeper insights about the concepts than they would when they are working alone. Learners could also be required to make up original problems to solve, after completing a regular homework exercise (Haak, HilleRisLambers, Pitre, \& Freeman, 2011).

\subsection{Cooperative Learning Groups}

Many teachers will occasionally break their classes into small groups for discussions, but only a few uses this technique as a fundamental teaching and learning device. A class can be divided into learning teams that are periodically given instructional tasks to complete, either in or out of class. Groups of around six or seven work best because this size is small enough for everyone to participate in problem-solving or debate yet large enough for a spectrum of views to be represented. To work successfully, groups require a wide variety of viewpoints and intellectual skills, so it is important to make them as heterogeneous as possible. The biographical data can yield important information about the learners' backgrounds and make it easier to create heterogeneous groups. A good teacher creates groups with maximum diversity with respect to gender, race, and other significant characteristics (Ambrose, Bridges, DiPietro \& Norman, 2010: 180-186).

The tasks you assign for group work should challenge learners to analyse a concept, solve problems, apply theories, exercise judgment or perform some combination of these activities. Clearly written instructions are vital to the success of this kind of exercise, which means the teacher must analyse the task carefully and break it down into its component parts. During the exercise once more, the teacher moves from group to group, answering questions, clarifying instructions, giving advice and observing the group process. In a well-designed group activity, there should be little need for direct intervention by the teacher. It is true that many teachers are uncomfortable with the loss of direct control that accompanies small-group work but you still manage the process and the goods by the instructions you provide for the groups. Small groups can be used with a variety of other techniques, such as peer teaching, case studies and simulations (Doyle, 2008).

\subsection{Case Studies}

The aim of case studies is to facilitate intuitive and integrated understanding of complex interconnected issues. Case studies also encourage learners to integrate theory into practice. Case studies can be used to enliven the material by making it concrete and relating it to the lived world (Doyle, 2011).

Case studies are appropriate for learning about information analysis, decision making, or problem-solving. The method requires the development of a set of cases that reflect problems or issues in the lesson. For example, in a human geography lesson, a case might describe the objects discovered in a real or hypothetical excavation. The learners, as a group, would be expected to infer information about the life and culture of the people who lived at the site, based on knowledge and techniques they had learned in other parts of the lesson (Smith, Sheppard, Johnson, and Johnson, 2005).

Depending upon the nature of the material and the intelligence of the learners, case studies can be quite lengthy and complex. The teacher can divide the class into small groups to work on the case and circulate among them to facilitate the process. As the year progresses, the cases can be made more complex and challenging as learners become more knowledgeable.

The development of case studies for an entire lesson requires research into the method to master its vagueness. Case studies must provide enough information to elicit analytical thought, but not so much that the solutions are obvious. This process can be very time-consuming, but once the cases are written, they may need only a few revisions to run 
successfully. Remember that learners need to master a common knowledge base before they will be ready to tackle a case study and they need to understand clearly the steps in the analytical process they will use. Finally, managing the discussion of case studies requires techniques that differ from generalized discussion methods and it would be helpful to observe a teacher experienced in this method before trying it personally (Haak, HilleRisLambers, Pitre, \& Freeman, 2011).

\subsection{Written Exercises}

Written exercises in class can be more original and exciting than the reports and homework exercises. Learners are capable of producing fairly sophisticated work if the exercise is clearly explained and carefully structured. For example, the teacher might require learners to observe and report on a school management meeting, gospel music competitions, bus station, or protest march. The teacher would need to teach the learners how to take observational notes and suggest a structured draft for the final report. To help learners sharpen writing skills, you may decide to assign shorter papers and allow rewrites until their work is acceptable. In general, many short writing exercises are preferable to a single long paper, depending upon the goals of the lesson and the level of learner skills. Regardless of the length of the exercise, clearly written instructions are vital (Berry, 2008).

Class time can be used for focused activities in which learners can practice essential skills. For example, in mathematics related subjects, after fifteen to twenty minutes of lesson on a particular type of problem, the teacher could require learners to work examples alone for fifteen minutes. This practice forces them to try to apply the concepts that have just been taught and usually produces questions they did not think to ask during the lesson. Since learners typically postpone their homework problems until the night before the next class, they often lose the thread of the explanation by that time and immediate practice in class helps reinforce the explanation (Haak, HilleRisLambers, Pitre, \& Freeman, 2011).

In addition, the lessons requiring learners to work homework problems on the chalkboard provides an opportunity to correct their errors and misconceptions and to ask questions about other homework problems while they are at the board. Other subjects that require short classroom exercises are similar to mathematics problems that are done in class. These exercises can take many different forms, for example, a paragraph defending or arguing against a particular point of view, a one-page analysis of a reading exercise or a short essay summarising the learner's impression of a class discussion. The variety of these short writing exercises is endless. They need not take huge amounts of class time and many can be accomplished in ten minutes or less (Zahorski, 1990).

\section{Active Learning Strategies}

When learners engage with each other in learning tasks, they remember material better and they figure out how to apply and extend their new knowledge more effectively. In addition, this approach promotes learning among learners from diverse needs and who have diverse learning styles. Active learning strategies are also simply more interesting, for the teacher and for the learners. Some kinds can be done with relatively little preparation; others require more careful logistical preparation (Berry, 2008).

To use active learning strategies effectively, the teacher should think through the learning objectives s/he want the learners to reach and pick a goal-appropriate activity. Be sure to plan the logistics of the activity in advance.

\subsection{Class Debate}

Class debate encourages learners to organize their thoughts in a critical or argumentative way that takes into account the complexity of issues and the existence of alternative and opposing views. To increase learners' public speaking and presentation skills, including the ability to think quickly on one's feet. Class debate can also be used to develop learners' research skills and give them a chance to become experts on a particular subject (Berry, 2008).

This strategy can be used with either large or small groups. In either case, it is often best to begin with a brief class discussion of the issues involved in the debate topic. This provides a context for the debate, a sense of the sub-issues involved, and a gauge of class feelings on the issues. At this time the teacher should also make clear the rules of the debate, including time allotted to each side and rules for speaking. If a small group format is used, divide the class into groups and give them time to choose their topic and resolution. After the sides and resolution are decided, the learners will need time to prepare their arguments and tactics. If the class is to perform the debate as a large group, the teacher usually serves as moderator. In this case, the two sides should also be given some time to develop their positions and 
their strategies of argument before the debate begins. In either a small- or large-group format, learners may be instructed to argue for their own beliefs or against them, depending on the teacher's objectives. Likewise, the teacher may choose to have learners argue first an affirmative position and then a negative one. Some teachers prefer to summarize the debate at the end; this can clarify the information presented and direct learners to focus on the key points derived from the exercise. Other teachers refrain from summarizing learners' contributions, thereby preserving the variety of opinions and perspectives that were expressed over the lesson of the debate (Ambrose, Bridges, DiPietro \& Norman, 2010: 180186).

\subsection{Role-Playing}

Role-Play's main objective is to increase learner awareness of the interconnectedness of knowledge and the indirect complexities of a situation to include affective learning as well as cognitive understanding, to expand personal experience by simulating a situation. Role-playing can be used to make learning more active (Zahorski, 1990).

Role plays may be done as a whole class or in small groups. The teacher begins by describing a context and a situation within that context. Learners are either given roles or allowed to choose them. Learners are given some time to prepare, and then they enter their roles and act out the situation. Some teachers add learner observers to the situations. These observers do not act out a role in the situation, but they observe and analyse the performances of the actors and provide feedback both to the actors and to the teacher and class. Role plays may be used even in fields which do not involve human beings directly: e.g., learners may play the roles of cells, molecules, economic forces and abstract philosophies in addition to historical figures (Barkley, 2005).

\subsection{Group Work Learning Strategy}

Group work is one pedagogical strategy that promotes participation and interaction. It fosters a deeper and more active learning process, and it also provides teachers with valuable demonstrations of the degree to which learners understand particular topics or concepts. In addition to exposing learners to different approaches and ways of thinking, working with other learners in groups can promote a sense of belonging that combats the anonymity and isolation that many learners experience at a large campus. Some learners may initially be reluctant to participate in group work, so sharing the reasons for group work with your learners can help to convince the reluctant ones. It might help them to know that research has shown that groups frequently devise more and better solutions than the most advanced individual (Barkley, 2005). Working together in groups also gives learners the opportunity to learn from and teach each other. Classroom research has shown that learners often learn better from each other than they do from a teacher (Barkley, 2005).

From a practical standpoint, group work also fosters interpersonal skills highly valued by employers, not to mention friends, neighbours and family. For teachers, group work can save some preparation time. Although preparing for effective group work does take some planning, it is less time-consuming than preparing a lesson. It is not difficult to incorporate group activities into your lesson plan, but there are some general rules of thumb about structuring group work so that it has useful outcomes for learners. Below are some basic guidelines to consider when designing a group activity, along with several kinds of group work learning techniques (Yorges, 2008).

Small groups or learning teams can be formed in four ways: randomly, teacher-selected, by seat proximity, or learner-selected. Random and teacher-selected group exercises avoid cliques and ensure that learners interact with different classmates throughout the semester.

Once you know your learners fairly well, teacher selection can be useful for grouping learners. Consider selecting groups or pairs with varying strengths and skill levels, since research has shown that groups of problem solvers with diverse skills consistently out-perform groups of problem solvers who are highly skilled in the same way (Davis, 2009).

During group work, as tempting as it may be, the teacher should not disengage from their class and sit at the front of the room! Circulate and listen to your learners. Are the learners on task or are they talking about their weekend plans? Are learners understanding the concepts and the exercise or are they all stuck and confused? Do they have questions for you? Pull up a chair and join each group for a while. On implementing group work for the first time in their section, some teachers find that the learners fall awkwardly silent when the teacher walks by or listens to their discussion. This is only temporary and it should stop once your learners are familiar with you and the group-work format. Because unfamiliarity drives this reaction, it is good to implement group work very early in the semester and to use it often in your section (Davis, 2009).

When a learner in a group asks you a question, the natural reflex is to answer it. Well, not exactly. Frequently a learner asking a question has not discussed it with the group yet and is not aware that members of the group either know 
the answer or have enough information to figure it out together. So, especially early on when the class is forming groupwork habits, it is important not to answer questions, at least not at first. Instead, ask the other group members how they would approach the question. If no one in the group has an idea, you can either give the group a start on how to answer it, consult with a different group on the question and finally answer the question yourself (Berry, 2008).

\subsubsection{Tips for formulating productive group-work exercises}

One common mistake that leads to failure in group work is that the exercise is too vague. For example, if you, as the teacher, tell your learners to discuss a particular concept, learners may make a few vague or general comments and then turn to discussing what they did over the weekend. Instead, make sure you have concrete and descriptive exercises. Ask questions that have more than one answer. Make the material that the groups will analyse in short, maybe just a short paragraph or a few sentences. Present it by means of a hand-out, overhead, chalkboard or another medium that all can easily see. If the material is longer, give concrete lines of questioning, which you display prominently or hand out. Understand that groups often take longer with longer material than their teacher anticipates which can produce frustration. Vary the format of the tasks (Yorges, 2008).

\subsubsection{Group work learning methods}

Group work usually involves groups of learners formally working together on projects or assignment, though it may sometimes take place in formal classroom settings. When setting group work activities, it can be useful to consider learner availability, teaching and learning resources necessary and expected results (Tlale, 2008). Hereunder follows the discussion on group work learning methods.

\subsubsection{Think-pair-share}

The teacher poses a question. Learners are given time (30 seconds or one minute) to think of a response. Each learner then pairs with another and both discuss their responses to the question. The teacher invites pairs to share their responses with the class as a whole.

\subsubsection{Structured controversy}

Divide the class into groups of four. The teacher identifies a controversial topic in the field covered in the lesson and gathers material that gives information and background to support different views of the controversy. Learners work with one partner, forming two pairs within the group of four. Each pair takes a different side of the issue. Pairs work outside of class or in class to prepare to advocate and defend their position. The groups of four meet, and each pair takes a turn stating and arguing its position while the other pair listens and takes notes without interrupting. Each pair must have a chance both to listen and take notes and to argue their position. Then all four talk together as a group to learn all sides of the issue. Next, each pair must reverse its position and argue the opposite position from the one it argued before. Lastly the group of four as a whole discusses and synthesizes all the positions to come up with a group report. There may be a class presentation in which each group presents its findings (Lang, 2007).

\subsubsection{Paired annotations}

Teacher with the involvement of the learners identify a number of significant articles on a topic. Each learner writes a reflective commentary on one article. In class, learners are randomly paired with another learner who has written a commentary on the same article. The two partners read each other's comments, comparing key points to their own commentary. The two learners, then team-write up a commentary based on a synthesis of both their papers (Barkley, 2005).

\subsubsection{Roundtable discussion}

Learners in small groups sit in a circle and respond in turn to a question by stating their ideas aloud as they write them on paper. The discussion can go around the circle more than once if desired. Learners discuss and summarize the ideas and report back to the class (Davis, 2009). 


\subsubsection{Three-Step Interview}

With this technique, the teacher can ask each learner to find one partner they don't know well. Make sure everyone has a partner. You can use threesome, if there is uneven number of learners in the class. Learners interview their partner for a limited amount of time using interview questions given by the teacher. Often questions should be experience-generated, for example, how do you use writing in your daily life? After a set time, learners switch roles so that both get a chance to be interviewed. Then, join each pair with another pair to form a group of four. Each partner in a pair introduces the partner to the other pair and summarizes the partner's responses (Yorges, 2008).

\subsubsection{Thinking-aloud paired problem solving}

Learners in pairs take turns thinking through the solution to a problem posed by the teacher. The learner who is not the problem solver takes notes and then the two learners switch roles so that each learner gets a chance to be both solver and note taker. Then they can go into larger teams or back to the class as a whole and report back about the solutions and the process (Byrnes and Byrnes, 2009).

\subsubsection{Peer editing}

Ask learners to hand in a first draft of a writing exercise. Photocopy each paper and identify it with a number instead of the learner's name. Give each learner in the class an anonymous paper to edit. It is helpful to give the learners verbal and written guidelines for editing criteria. After the learners edit a paper, each learner receives the anonymous feedback from his or her unknown peer editor. It is often useful to have a class discussion about how this process worked for everyone (Davis, 2009).

\subsubsection{Reciprocal peer questioning}

The teacher gives out class reading on a topic as homework. The teacher asks learners to generate a list of two or three thought-provoking questions of their own on the reading. Learners bring the questions they have generated to class. Learners do not need to be able to answer the questions they generate. Learners then break into teams of three to four. Each learner poses her questions to the team and the team discusses the reading using the learner-generated questions as a guide. The questions of each learner are discussed within the team. The team may then report back to the class on some key questions and the answers they came up with (Felder, 2011).

\section{Conclusion}

John Dewey and other advocates have suggested active learning, because it is grounded solidly in the biological basis of learning and because it has been increasingly researched and reviewed, is not just the latest academic fashion. On the contrary, active learning is a well-tested approach that teachers committed to learner learning should consider adopting. Intentionality provides the key to using active learning effectively, just as purposeful teaching helps faculty members use cooperative learning and other approaches that lead to deep learning. Teamwork and problem solving result in strong pedagogical gains and concludes that learners need to attend classes that set their minds on fire (Felder, 2011).

\section{References}

Ambrose, S. A., Bridges, M.W., DiPietro, M. \& Lovett, M.C. (2010). How learning works: Seven research-based principles for smart teaching. San Francisco, CA: Jossey Bass.

Barkley, E. (2005). Collaborative Learning Techniques. San Francisco: Jossey-Bass.

Berry, W. (2008). Surviving lesson: A pedagogical alternative. The school Teaching, 56(3), 149-154.

Bligh, D. A. (2000). What's the use of lessons. San Francisco: Jossey-Bass.

Bonwell, C., \& Eison, J. (1991). Active learning: Creating excitement in the classroom (ASHE-ERIC Higher Education Report No. 1). Washington, DC: George Washington University.

Bloom, B. S. (1956). Taxonomy of educational objectives-The classification of educational goals: Handbook I. - Cognitive domain. NY: David McKay.

Braxton, J. M., Milem, J. F., \& Sullivan, A. S. (2000). The influence of active learning on the the school learner departure process: Toward a revision of Tinto's theory. The Journal of Higher Education, 71(5), 669-590. 
Brookfield, S. D. (1987). Developing critical thinkers: Challenging adults to explore alternative ways of thinking and acting. San Francisco: Jossey-Bass.

Byrnes, Joseph F. and Mary Ann Byrnes (2009). "Dealing with Learners Who Hate Working in Groups." Effective Group Work Strategies for the The school Classroom. Madison: Magna Publications, 6-7

Cameron, B. (1999). STLHE Green Guide No. 2: Active Learning. Halifax, CA: Society for Teaching and Learning in Higher Education.

Davis, B. G. (2009). Tools for Teaching, 2nd ed. San Francisco: Jossey-Bass.

Doyle, T. (2011). Learner-centered teaching: Putting the research on learning into practice.

Sterling. VA: Stylus Publishing.

Felder, R. M (2011). Hang in there: Dealing with learner resistance to learner-centered teaching. Chemical Engineering Education, 45(2), 131-132.

Haak, D. C., HilleRisLambers, J., Pitre, E., \& Freeman, S. (2011). Increased structure and active learning reduce the achievement gap in introductory biology.

Lang, J. M. (2007). Classroom transparency. The Chronicle of Higher Education, 53(31).

Millis, B. J. (2002). IDEA Paper No. 38: Enhancing learning -and More!-through cooperative learning. Manhattan, KS: The IDEA Center.

Smith, K. A., Sheppard, S. D., Johnson, D. W., \& Johnson, R. T. (2005). Pedagogies of Engagement: Classroom-Based Practices. Journal of Engineering Education, 1-15.

Stuart, J. \& Rutherford, R. J. (1978). Medical learner concentration during lessons. The Lancet, 514-516.

Tlale, L.D.N. (2008). Educators' perceptions about learners with barriers to learning and development in the implementation of Inclusive Education. M.Ed. dissertation Mafikeng: North West University.

Wilson, K. \& Korn, J.H. (2007). Attention during Lessons: Beyond Ten Minutes. Teaching of Psychology, (34) 2, 85-89.

Yorges, S. L. (2008). Providing "realistic lesson previews" to enhance learning and satisfaction. APS Observer.

Zahorski, K. J. (1990). Removing the screen: The real magic of learning partnerships.

Keynote address given at University of Maryland University The school. 